\title{
CORRECTION
}

\section{Correction to: Traumatic inferior shoulder dislocation: a review of management and outcome}

\author{
Mithun Nambiar ${ }^{1} \cdot$ David Owen $^{2} \cdot$ Peter Moore ${ }^{3} \cdot$ Ashley Carr $^{4} \cdot$ Malcolm Thomas $^{2}$
}

Published online: 20 November 2017

๑) Springer-Verlag GmbH Germany, part of Springer Nature 2017

\section{Correction to: Eur J Trauma Emerg Surg https://doi.org/10.1007/s00068-017-0854-y}

The original version of this article unfortunately contained mistakes.
The presentation of the author names was incorrect. The correct author list is given above. The original article was corrected.

The original article can be found online at https://doi. org/10.1007/s00068-017-0854-y.

Mithun Nambiar

mithunnambiar1@gmail.com

David Owen

david.h.owen@gmail.com

Peter Moore

p.jmoore@bigpond.com

Ashley Carr

dr.ashleycarr@gmail.com

Malcolm Thomas

mdthomas1@gmail.com

1 Department of Orthopaedics, The Royal Melbourne Hospital, Parkville, VIC, 3050, Australia

2 Department of Orthopaedics, La Trobe Regional Hospital, Traralgon, VIC, 3844, Australia

3 Department of Orthopaedics, Northern Hospital, Epping, VIC, 3076, Australia

4 Melbourne Orthopaedic Group, Windsor, VIC, 3181, Australia 